\title{
PERFIL DOS COMERCIANTES E CONSUMIDORES DE PLAN- TAS ORNAMENTAIS EM CURITIBA-PR
}

\author{
Profile of traders and consumers of \\ ornamental plants in Curitiba-Paraná
}

\author{
Ana Paula Conter Lara* \\ Ruy Inácio Neiva de Carvalho**
}

\section{Resumo}

Este trabalho foi realizado com o objetivo de caracterizar o perfil de comerciantes e consumidores de plantas ornamentais em Curitiba, Paraná. O perfil dos comerciantes foi avaliado por meio de entrevistas em 34 estabelecimentos da cidade e o dos consumidores por meio de entrevistas a 80 pessoas selecionadas aleatoriamente. Constata-se que os estabelecimentos que comercializam flores em Curitiba são abertos sem pesquisa de mercado e $55 \%$ deles não exigem experiência para a contratação de funcionários. Há deficiências na área de marketing, pois $41 \%$ das floriculturas se restringem à distribuição de cartões. A maior parte (76\%) dos produtos comercializados é adquirida de São Paulo. A maioria dos consumidores costuma comprar flores eventualmente (63\% dos entrevistados), com o objetivo de dar como presente (74\%) e em estabelecimentos próximos à sua residência (64\%).

Palavras-chave: Planejamento, Mercado, Floriculturas.

\section{Abstract}

This work aimed to evaluate the profile of traders and consumers of ornamental plants in Curitiba, Parana, Brazil. Traders profile was evaluated through an interview in 34 establishments in the city. Eighty people were interviewed to make a general consumers profile of this kind of business. Flower shops are open without market research and $55 \%$ do not require experienced people to begin the job. Marketing is deficient because $41 \%$ of establishments only distribute visiting cards. São Paulo is the main supplier of products. The consumer buy flowers eventually (63\%), mainly to give them as gifts (74\%) and do this in establishments close to his house. Keywords: Planning, Marketing, Flower shops.

\footnotetext{
Aluna de Agronomia. Centro de Ciências Agrárias e Ambientais. Pontifícia Universidade Católica do Paraná.

"* Eng. Agrônomo, Dr., CREA-PR 024342/D, Professor Adjunto do Curso de Agronomia do Centro de Ciências Agrárias e Ambientais da Pontifícia Universidade Católica do Paraná.

Rodovia BR 376, km 14. Caixa Postal 129, São José dos Pinhais - PR, CEP 83010-500.

E-mail: ruycarvalho@zipmail.com.br
} 


\section{Introdução}

Até a década de 1950 a atividade de floricultura era vista como bobby no Brasil e apenas começou a se destacar como atividade agrícola econômica no estado de São Paulo. Na década de 1990, São Paulo deteve 70 \% da produção brasileira, seguido por Minas Gerais, Rio de Janeiro e Santa Catarina. O município de Holambra, SP, é o maior produtor de flores e plantas da América Latina, respondendo por cerca de $30 \%$ do mercado com produtos muito procurados para revenda em floriculturas locais (AKI, 1998; BONGERS, 1995; IBRAFLOR, 1989).

Juntamente com a expansão da produção de flores no Brasil houve também crescimento do mercado varejista e das vendas informais, fato que provocou a desvalorização do produto pela desorganização do mercado. Esta desordem resultou em um baixo consumo por habitante, atingindo em 2000 o valor de US\$24,00 ao ano, enquanto na Suíça, país de maior consumo, os valores registrados foram de US\$ 184,00 por habitante ao ano (ALMEIDA; AKI, 1995; IBRAFLOR, 1989).

O mercado de flores não está indiferente ao que acontece na economia brasileira e a situação atual reflete uma preocupação com o comércio em geral. A necessidade e a importância de caracterização do mercado de produtos hortícolas podem ser exemplificadas por diversas pesquisas realizadas com frutas comercializadas em mercados atacadistas e varejistas de vários estados brasileiros (CARVALHO et al., 1992; FAGUNDES et al., 1999; FAGUNDES et al., 2000; FAGUNDES; YAMANISHI, 2001; FIORAVANÇO et al., 1994; PAIVA et al., 1996).

Em virtude de a maioria da produção de plantas ornamentais no norte do Paraná ser comercializada na CEASA de São Paulo, em 1992 foi implantado em Curitiba o mercado de flores da CEASA-PR que apresentou grande potencial de exploração e necessidade de estruturação (MORIMOTO, 1997). Este aumento de exploração do mercado também estimulou a procura de flores durante todo o ano e a abertura de novas floriculturas, porém há falta de informações locais para definição de um perfil deste mercado emergente.

O objetivo deste trabalho é caracterizar o perfil dos comerciantes e consumidores de plantas ornamentais em Curitiba, Paraná.

\section{Materiais e métodos}

O levantamento de dados sobre o comércio de flores em Curitiba foi realizado no período de maio a setembro de 2001 por meio de aplicação de questionários a comerciantes e consumidores.

Para o levantamento do perfil do comerciante foram selecionadas aleatoriamente 34 floriculturas distribuídas em 11 bairros de classes alta, média e baixa renda. Os questionários foram aplicados a proprietários e vendedores responsáveis pela floricultura. Foram elaboradas perguntas sobre a floricultura (motivo pela opção do ramo, tempo de funcionamento, propriedade do imóvel, procedência dos produtos comercializados, forma de divulgação e prestação de serviços diferenciados), os funcionários (exigências para contratação, treinamento e número) e os consumidores que as freqüentam (freqüência de compra, tipo de freguesia e o produto mais procurado).

Para o levantamento do perfil do consumidor foram entrevistadas 80 pessoas de diferentes idades, formações e níveis socioeconômico, abordadas em escolas, residências e universidades. O questionário foi elaborado para obtenção de informações a respeito de freqüência de compra, motivo da compra e a escolha da floricultura. Os dados coletados foram tabulados e calculou-se a freqüência de cada resposta obtida.

\section{Resultados}

Conforme as respostas obtidas observouse que o motivo da escolha do ramo de floriculturas pelos comerciantes foi, preferencialmente, por gostar desta atividade (32\%). Outros 24\% escolheram por seguir opção da família, $21 \%$ por experiência anterior, $12 \%$ não sabiam o motivo, $6 \%$ por perspectivas de lucro e $5 \%$ não responderam. Ficaram sem resposta as opções de pesquisa de mercado e região sem concorrência. Verificou-se que a opção por este ramo não teve base em planejamento prévio e este fato pode prejudicar o desenvolvimento e consolidação da empresa no mercado. Por outro lado, a maior parte das floriculturas funciona há mais de dez anos (38\%), seguido de cinco anos (26\%), três anos (12\%) e há um ano ou menos (12\%). Outros $12 \%$ não responderam esta pergunta.

Com relação à propriedade do imóvel, 
$35 \%$ pagam aluguel, $6 \%$ arrendam e 18\% são proprietários e os outros $41 \%$ não responderam. As floriculturas em imóveis alugados representam um fator negativo para o mercado, pois há maior possibilidade de mudança do estabelecimento, não contribuindo para a formação de um ponto tradicional de mercado de plantas.

A maioria das floriculturas admite comprar as flores de São Paulo, num total de $76 \%$. Outros 11\% comercializam produtos de Curitiba, $8 \%$ comercializam sua própria produção e $5 \%$ compram produtos de Santa Catarina. A falta de produtores especializados em Curitiba e Região Metropolitana, bem como a falta de divulgação de produtores existentes, contribuem para o desconhecimento das floriculturas a respeito de onde adquirir plantas no mercado próximo.

A divulgação das floriculturas é realizada principalmente por meio de cartões (41\%), seguidos por jornal (10\%), televisão (7\%), rádio (7\%), distribuição de folhetos (7\%), internet (3\%), revista para decoração (3\%), panfletos (3\%), placas (3\%), faixas (3\%), ímãs (3\%) e os 10\% restantes não fazem propaganda. A deficiência na propaganda das floriculturas não favorece a procura pelo consumidor.

Com relação a serviços diferenciados oferecidos, 25\% atendem a encomendas de clubes, $21 \%$ produzem coroas para funerais, $18 \%$ fazem projetos de paisagismo, $15 \%$ oferecem o serviço de entrega, $6 \%$ confeccionam cestas de café-damanhã e $15 \%$ não oferecem serviços diferenciados.

A maioria dos funcionários é contratada sem exigência de experiência no ramo (55\%). Apenas 15\% exigem curso na área, 3\% exigem segundo grau, $6 \%$ curso superior, $6 \%$ especialização, $6 \%$ experiência anterior, 3\% treinamento e $6 \%$ não responderam. Após a contratação, 64\% dos funcionários não participam de treinamento, 30\% participam de qualquer tipo de treinamento e $6 \%$ não responderam. Assim, os serviços oferecidos não são acompanhados de orientações adequadas ao consumidor, prejudicando o sucesso na comercialização. Quanto ao número de funcionários, 84\% das floriculturas têm de um a três funcionários ou são atendidas pela própria família e 16\% têm mais de quatro funcionários.

Quanto ao consumidor que visita a floricultura, 59\% sempre compram flores, 29\% compram em datas festivas e somente $12 \%$ compram às vezes. A maioria das floriculturas (74\%) tem uma freguesia fixa enquanto $14 \%$ dizem ter fregueses eventuais e $12 \%$ não responderam.

Quanto ao tipo de freguesia, 41\% alegam ser formada igualmente por homens e mulheres, $35 \%$ principalmente por mulheres, 15\% principalmente por homens e 9\% não responderam. Observou-se que as mulheres são os principais consumidores de plantas ou flores comprando tanto para presente como para decoração. O produto mais procurado é o buquê de rosas (38\%) seguido por flores em buquê (18\%), flores em vaso (15\%), arranjos (15\%), flores ou plantas para jardim (11\%) e mudas (3\%).

Com relação ao perfil do consumidor, observou-se que $63 \%$ dos entrevistados costumam comprar flores às vezes, $15 \%$ compram raramente, $12 \%$ nunca compram e 10\% sempre compram. Constatou-se assim que a maioria das pessoas não tem o hábito de comprar flores freqüentemente. Mas, de acordo com as informações dos comerciantes, a maioria que freqüenta a floricultura (59\%) sempre compra flores.

A maioria dos entrevistados (74\%) compra flores para presente, 25\% para decoração e $10 \%$ por hábito, salientando que alguns entrevistados responderam mais de uma das alternativas. As flores cortadas, principalmente o buquê de rosas, são as mais procuradas para presentes, mas o custo dos produtos ainda afasta os consumidores que acabam optando por outras alternativas quando o motivo é presentear.

A maioria dos entrevistados (64\%) escolhe a floricultura pela proximidade à residência, $21 \%$ por pesquisa de mercado, $12 \%$ por recomendação e 3\% pela divulgação. Como não há eficiente divulgação das floriculturas a maioria dos consumidores escolhe a floricultura pelo simples fato de serem mais próximas da sua residência, do seu trabalho ou por que coincidem com seu trajeto habitual.

\section{Considerações Finais}

- Constata-se que os estabelecimentos que comercializam flores em Curitiba são abertos sem pesquisa de mercado e 55\% deles não exigem experiência para a contratação de funcionários.

- Há deficiências na área de marketing, pois $41 \%$ das floriculturas se restringem à distribuição de cartões e 10\% não fazem qualquer pro- 
paganda. A maior parte $(76 \%)$ dos produtos COmercializados é adquirida de São Paulo.

- A maioria dos consumidores costuma comprar flores eventualmente (63\% dos entrevistados), com o objetivo de dar como presente (74\%) e em estabelecimentos próximos à sua residência (64\%).

\section{Referências}

AKI, A. Repensando a comercialização de flores. São Paulo, SP: Bandeirantes, 1998. 110 p.

ALMEIDA, F. R. F.; AKI, A.Y. Grande crescimento no mercado de flores. Agroanalysis, Rio de Janeiro, v. 15, n. 9, p. 8-11, 1995.

BONGERS, F. J. G. A economia das flores. Agroanalysis, Rio de Janeiro, v. 15, n. 9, p. 1-7, 1995.

CARVALHO, R. I. N.; FIORAVANÇO, J. C.; PAIVA, M. C.; MANICA, I. Características físicas e químicas do mamão "papaya" comercializado em Porto Alegre. Revista Brasileira de Fruticultura, Cruz das Almas, v. 14, n. 1, p. 143-147, 1992.

FAGUNDES, G. R.; YAMANISHI, O. K.; BORGO, L. A.; MANICA, I. Atributos de qualidade da banana 'Prata' comercializada entre setembro/97 e agosto/ 98, em 4 estabelecimentos de Brasília-DF. Revista Brasileira de Fruticultura, Jaboticabal, v. 21, n. 3, p. 372-374, dez. 1999.
FAGUNDES, G. R.; YAMANISHI, O. K.; MANICA, I.; LACERDA, C. S. Sazonalidade do abacaxi 'Pérola' nas CEASAs do Distrito Federal, São Paulo, Belo Horizonte e Rio de Janeiro, a partir do plano real. Revista Brasileira de Fruticultura, Jaboticabal, v. 22, n. 2, p. 253-256, ago. 2000.

FAGUNDES, G. R.; YAMANISHI, O.K. Quantidade e preços da banana 'Prata' comercializada nas CEASAS do Distrito Federal, São Paulo, Belo Horizonte e Rio de Janeiro no período de 1995 a 1999. Revista Brasileira de Fruticultura, Jaboticabal, v. 23, n. 3, p. 593-596, dez. 2001.

FIORAVANÇO, J. C. et al. Oferta de abacaxi nas CEASAS do Rio Grande do Sul, Santa Catarina e Paraná. Ciência Rural, Santa Maria, v. 24, n. 1, p. 73-76, 1994

IBRAFLOR. Números do mercado brasileiro de flores. São Paulo: Instituto Brasileiro de Floricultura, 1989. $7 \mathrm{p}$.

MORIMOTO, A. Produção de flores. Curitiba: CEASA, 1997. $16 \mathrm{p}$

PAIVA, M. C. et al. Características da banana "nanicão" comercializada em Porto Alegre de outubro de 1991 a junho de 1992. Ciência e Agrotecnologia, Lavras, v. 20, n. 3, p. 275-278, jul/ set, 1996. 